\title{
Der Systemwechsel bringt eine bessere Lösung als die bisherige
}

\section{Stefan Ritler}

Leiter Invalidenversicherung, Bundesamt für Sozialversicherungen BSV

Korrespondenz: Stefan Ritler Bundesamt für Sozialversicherungen Effingerstrasse 20 CH-3003 Bern Tel. 0313229011 Fax 0313227880

info@bsv.admin.ch

www.bsv.admin.ch
Die Lage der Invalidenversicherung ist kein Grund zum Schmunzeln. Die IV ist faktisch bankrott. Die Leistungen, die sie gewährt, kann sie nur darum bezahlen, weil sie bis heute 3,7 Milliarden Franken aus der Soldatenkasse und 5 Milliarden von der AHV geschenkt bekam, weil sie der AHV einen ungedeckten 15-Milliarden-Scheck hinterlassen konnte und darüber hinaus von den Konsumenten pro Jahr mit 1,1 Milliarden Franken aus der Mehrwertsteuer «über Wasser» gehalten wird. Sieben Jahre hat die IV nun Zeit, die Ausgaben so weit zu reduzieren, dass sie auf eigenen Beinen stehen kann, denn die Zusatzfinanzierung fällt nachher wieder weg. Das ist der bittere Ernst der Invalidenversicherung.

Auf der anderen Seite ist bekannt - und von unabhängigen Stellen wie der Eidgenössischen Finanzkontrolle und dem Preisüberwacher bestätigt -, dass bei der Versorgung mit Hörgeräten mehrstellige Millionenbeträge buchstäblich versickern. Kaum jemand, der daran beteiligt ist, hat einen Anreiz, sich wirtschaftlich vernünftig zu verhalten. Es besteht sogar der begründete Verdacht, dass der Wettbewerb in dieser Branche mit unzulässigen Preisabreden behindert wird, wie die Eidgenössische Wettbewerbskommission Mitte März bekanntgab.

Diese Situation ist doch einfach pervers: Auf der einen Seite muss der Bundesrat Leistungskürzungen für Behinderte - insbesondere bei den IV-Renten und den Kinder-Zusatzrenten - vorschlagen, um die Volksversicherung zu retten, auf der anderen Seite versickern Millionenbeträge ohne jeglichen Nutzen für die Hörbehinderten in einem undurchsichtigen Versorgungssystem. Die IV kann und will sich das nicht länger leisten.

Eine zentrale Ausschreibung der Hörgeräte durch den Bund wäre eine geeignete Lösung gewesen, um eine qualitativ hochstehende Versorgung zu vernünftigen Kosten zu gewährleisten. Dagegen wehrte sich aber die betroffene Branche mit Hilfe von teuren Lobbyisten. Die Desinformation mit der Mär vom Staatseinkauf und veralteten Einheitsgeräten verfehlte ihre Wirkung offenbar nicht, obwohl praktikable logistische Lösungen in Vorbereitung waren und auch mit einer Ausschreibung weit über 200 verschiedene moderne Gerätetypen zur Auswahl stünden. Schliesslich stoppte das Bundesverwaltungsgericht die Ausschreibung, weil ihm die gesetzliche Grundlage dafür nicht ausreichend schien.

Das Parlament hat die gesetzliche Grundlage inzwischen geschaffen, aber vorgeschrieben, dass zuerst mit anderen Möglichkeiten versucht werden muss, die Kosten für die Versorgung zu senken. Daher setzt das BSV nun das um, was die Eidgenössische Finanzkontrolle, die Hörgerätebranche, Behinderte selber und das Parlament mit mehreren Vorstössen gefordert haben: ein System, das Kosten spart, indem die Hörbehinderten als selbstverantwortliche, eigenständige und kostenbewusste Kunden für Wettbewerb und tiefere Preise sorgen - bei gleichzeitig hoher Qualität des Angebots. Die Pauschalen, die die IV für die Hörgeräte bezahlen wird, sind dafür hoch genug, die Hörgeräte müssen ein Zulassungsverfahren bestehen, und die Versorgung muss durch eine Fachperson erfolgen.

Es war unvermeidlich, dass die Konzeption einer neuen Lösung und die Versorgung nach dem alten System eine Zeitlang parallel laufen. Selbstverständlich wurde auch das bisherige System weitergepflegt, bis die Alternative beschlussreif war. Das hat nichts damit zu tun, dass die ORL-Spezialistinnen und -Spezialisten hintergangen werden sollten. Wer ein neues Auto braucht, muss ja seinen alten Wagen trotzdem fahrtüchtig halten, bis der neue in der Garage steht.

Es ist verständlich, dass die ORL-Ärzte der Schlussexpertise nachtrauern. Aber die IV kann es sich nicht leisten, etwas zu verlangen und zu bezahlen, das im System der Pauschalvergütung objektiv keinen Sinn mehr macht. Bisher konnte die IV bei einer negativen Expertise dem Akustiker die Zahlung verweigern, doch diese Möglichkeit entfällt, wenn die Vergütung nicht mehr dem Verkäufer, sondern dem Käufer zusteht.

Die IV kann es nicht verantworten, die überteuerte Vollkaskoversorgung zu erhalten. Sie hat darum einen Systemwechsel vollzogen, der vielleicht noch nicht die allerbeste, aber auf jeden Fall eine viel bessere Lösung bringt als die bisherige. 